\title{
O PET-EDUCAÇÃO NO CONTEXTO DA FORMAÇÃO ACADÊMICA: AS LICENCIATURAS EM EVIDÊNCIA
}

\author{
EL PET-EDUCACIÓN EN EL CONTEXTO DE LA FORMACIÓN ACADÉMICA: \\ LAS LICENCIATURAS EN EVIDENCIA
}

\author{
PET-EDUCATION IN THE CONTEXT OF ACADEMIC TRAINING: THE \\ TEACHER DEGREES IN EVIDENCE
}

\author{
Mardem Michael Ferreira da SILVA ${ }^{1}$ \\ João Paulo de SOUZA ${ }^{2}$ \\ Luciano Bernardes LEITE ${ }^{3}$ \\ Bárbara Alves de MORAIS ${ }^{4}$ \\ Camila Lopes ALMEIDA ${ }^{5}$ \\ Larissa Gabrielle Ferreira da SILVA ${ }^{6}$ \\ Sarah Vieira MIRANDA ${ }^{7}$ \\ Mayra Cristina da Silva COSTA ${ }^{8}$ \\ Vívian Helene Diniz ARAÚJO9
}

RESUMO: A formação extracurricular durante a graduação é um fator de extrema importância para a ampliação das vivências do estudante durante a sua vida acadêmica. Alguns programas existentes na universidade, como o Programa de Educação Tutorial PET, por exemplo, possibiltam ao aluno experiências com essa formação, que vai além do que é abordado nas disciplinas dos cursos. Seguindo a prerrogativa PET em nível nacional, o PET-EDUCAÇÃO da Universidade Federal de Viçosa (UFV), campus Florestal, trabalha visando abranger os cursos de graduação do campus a que pertence, mas tendo como foco principal as licenciaturas. Nesse sentido, esse estudo objetivou a obtenção de informações sobre qual a contribuição do grupo PET-EDUCAÇÃO para a formação acadêmica dos alunos do campus Florestal/UFV, em suas percepções. Por

\footnotetext{
1 Universidade Federal de Viçosa (Ufv), Viçosa - MG - Brasil. Bolsista PET-Educação. E-mail: mardemmichael@yahoo.com.br.

${ }^{2}$ Universidade Federal de Viçosa (Ufv), Viçosa - MG - Brasil. Docente do Instituto de Ciências Biológicas e da Saúde da UFV florestal. Doutor em Ecologia e Recursos Naturais pela UFSCAR. E-mail: joaopaulobio@hotmail.com.

3 Universidade Federal de Viçosa (Ufv), Viçosa - MG - Brasil. Bolsista PIBIC. E-mail: luciano.leite@ufv.br.

4 Universidade Federal de Viçosa (Ufv), Viçosa - MG - Brasil. Bolsista PET/Educação. E-mail: barbara.a.morais@ufv.br.

5 Universidade Federal de Viçosa (Ufv), Viçosa - MG - Brasil. Bolsista PET/Educação. E-mail: mila.loopes@hotmail.com.

6 Universidade Federal de Viçosa (Ufv), Viçosa - MG - Brasil. Bolsista PIBIC. E-mail: larissa.gabrielle@ufv.br.

7 Universidade Federal de Viçosa (Ufv), Viçosa - MG - Brasil. Bolsista PET/Educação. E-mail: sarah.v.miranda@ufv.br.

${ }^{8}$ Universidade Federal de Viçosa (Ufv), Viçosa - MG - Brasil. Bióloga, licenciada pela UFV. E-mail: mayracsc@ hotmail.com.

${ }^{9}$ Universidade Federal de Viçosa (Ufv), Viçosa - MG - Brasil. Química, licenciada pela UFV. E-mail: vivian.diniz@ufv.br
} 
meio da aplicação de questionário semiestruturados, ficou evidente que o PETEDUCAÇÃO é conhecido pelos graduandos do campus em questão, mas que nem todos estes participam de suas atividades, principalmente devido à falta de tempo. O programa exerce uma notável contribuição para a formação dos graduandos, em especial dos estudantes das licenciaturas.

PALAVRAS-CHAVE: Formação acadêmica. Formação extracurricular. Formação de professores.

RESUMEN: La formación extracurricular durante la graduación es un factor de extrema importancia para la ampliación de las vivencias del estudiante durante su vida académica. Algunos programas existentes en la universidad, como el Programa de Educación Tutorial - PET, por ejemplo, posibilitan al alumno experiencias con esa formación que va más allá de lo que se aborda en las disciplinas de los cursos. El PETEDUCACIÓN de la Universidad Federal de Viçosa (UFV), campus Forestal, trabaja para abarcar los cursos de graduación del campus al que pertenece, pero teniendo como foco principal las licenciaturas, siguiendo la prerrogativa PET a nivel nacional. En este sentido, este estudio objetivó la obtención de informaciones sobre cuál la contribución del grupo PET-EDUCACIÓN para la formación académica de los alumnos del campus Forestal / UFV, en sus percepciones. Por medio de la aplicación de cuestionarios semiestructurados, quedó evidente que el PET-EDUCACIÓN es conocido por los graduandos del campus en cuestión, pero que no todos éstos participan de sus actividades, principalmente debido a la falta de tiempo. El programa ejerce una notable contribución a la formación de los graduados, en particular de los estudiantes de las licenciaturas.

PALABRAS CLAVE: Formación académica. Formación extracurricular. Formación de profesores.

ABSTRACT: The extracurricular training during graduation is a factor of extreme importance for the amplification of the experiences of the student during his academic life. Some existing programs in the university, such as the Education Program Tutorial PET, for example, allow the student experiences with this training that goes beyond what is covered in the courses of the courses. Following the prerogative of the Tutorial Education Program (PET) at the national level, the PET-EDUCAÇÃO of the Federal University of Viçosa (UFV), campus Florestal, works to cover undergraduate courses of the campus to which it belongs, but focusing on teacher education. In this sense, this study aimed to obtain information about the perceptions of contribution of PETEducação to the academic education of campus Florestal/UFV undergraduate students. Through the application of a semi-structured questionnaire, it was evident that PETEDUCATION is known by the undergraduates of the campus in question, but not all of them participate in their activities, mainly due to lack of time. The program makes a notable contribution to the training of undergraduates, especially teacher degree students.

KEYWORDS: Academic training. Extracurricular training. Teacher training. 


\section{Introdução}

Durante a formação acadêmica de um indivíduo, existe a necessidade de que o mesmo se envolva em programas e/ou projetos que complementem a formação que lhe é oferecida em sala de aula. Essa formação é chamada de formação extracurricular ou complementar (GERBER, 1996; PEREIRA et al, 2011).

Alguns estudos apontam para a importância da formação complementar adquirida por meio da participação em programas de iniciação científica e à docência, minicursos, seminários, oficinas, dentre outros (BROH, 2002; SIMÃO et al, 2005; PEREIRA et al, 2011). Essa formação externa à oferecida em sala de aula possibilita um acesso a outros conhecimentos que vão além dos inerentes à futura profissão que se aprende no curso, potencializando capacidades de trabalhar em grupo, de se expressar, organizar dados, administrar o tempo e as situações (BROH, 2002).

Nesse contexto, foram implantados nas universidades alguns programas que favorecem o contato do aluno com essa formação extraclasse. O Programa de Educação Tutorial (PET) se destaca por sua natureza dinâmica e permeada pelos três pilares que regem a universidade pública - o ensino, a pesquisa e a extensão (MARTIN, 2005; PERES, BOSCARIOLI, 2011).

Na Universidade Federal de Viçosa (UFV), no campus Florestal, em Minas Gerais, o PET tem como área central a educação, denominando-se PET-EDUCAÇÃO. Essa ênfase foi necessária, uma vez que existem cinco cursos de licenciatura nesse campus, ampliando assim o alcance do programa no campus Florestal/UFV.

Em se tratando de licenciaturas e formação docente, sabe-se que esta enfrenta diversos desafios, com cursos que muitas vezes versam entre o bacharelado e a licenciatura, tendo seus conhecimentos concentrados principalmente nas áreas específicas da matéria a ser lecionada em detrimento dos conhecimentos relacionados às ciências da educação e ensino da matéria (GATTI, 2010; CHAVES, TERREZAN, 2015; DA SILVA et al, 2016). A formação extracurricular na área pedagógica pode ser uma forma de atenuar os efeitos da formação dicotômica que é oferecida nos cursos de licenciatura (BIASUS, 2006).

Sabendo da importância da participação em atividades extracurriculares para os estudantes de uma forma geral, o PET-EDUCAÇÃO, com o apoio da direção do campus Florestal/UFV, procura proporcionar experiências para os graduandos de todos os cursos em variados campos do conhecimento, na tentativa de sanar a carência dessas 
atividades no campus, que ainda é recente na implantação de cursos superiores (que começou no ano de 2008). Portanto, desde sua criação, em 2010, o programa trabalha nesse sentido.

A fim de se estabelecer um panorama de como os estudantes percebem o trabalho do PET-EDUCAÇÃO e obter informações que auxiliem em um melhor planejamento das atividades e ações para a melhoria do programa é que esse estudo foi proposto. $\mathrm{O}$ objetivo foi saber se os alunos conheciam o programa e suas atividades e qual as percepções dos alunos em relação à contribuição do PET para a sua formação acadêmica.

\section{O Programa PET}

A Coordenação de Aperfeiçoamento de Pessoal de Nível Superior (CAPES) criou o PET em 1979, com o nome de Programa Especial de Treinamento, tendo como principal objetivo o incentivo e a preparação dos estudantes de graduação para ingressarem em programas de pós-graduação. No entanto, em 1999, o PET, passando a chamar Programa de Educação Tutorial, foi reformulado pela Secretaria de Educação Superior, no Ministério da Educação (MEC). Assim, os objetivos do programa passaram a ser focados na melhoria dos cursos de graduação e no desenvolvimento da consciência social e cidadania em seus participantes (USP, 2009).

O PET pressupõe a criação de um grupo formado por uma média de 12 alunos que tem um professor como tutor. $\mathrm{O}$ grupo é focado em realizar atividades que contemplem o ensino, a pesquisa e a extensão. Os alunos do programa (chamados de petianos) e os tutores recebem bolsas que são estabelecidas e gerenciadas pelo governo federal, podendo também haver petianos voluntários participando dos grupos (PET, 2006). As atividades realizadas pelos grupos PET podem trazer diversos benefícios aos participantes, pois permitem uma formação acadêmica ampla, trabalho com interdisciplinaridade, atuação em grupo e o planejamento e execução de projetos (PERES, et al, 2006).

\section{O PET-EDUCAÇÃO do campus Florestal/UFV}

Criado em 2010, o PET-EDUCAÇÃO da Universidade Federal de Viçosa, campus Florestal - MG, está vinculado a cinco licenciaturas - Ciências Biológicas, 
Educação Física, Física, Matemática e Química. Seguindo os objetivos que prevê o programa em nível nacional, o PET-EDUCAÇÃO visa trabalhar não somente para a melhoria da formação dos petianos e graduandos dos cursos ao qual o PET é vinculado, mas também dos graduandos dos demais cursos da instituição. Assim, esse programa procura realizar atividades que possam abranger o maior número de cursos possíveis, cumprindo uma de suas funções, que é a melhoria dos cursos de graduação. Compete também ao programa realizar atividades de cunho extensionista junto a escolas da região e à comunidade do entorno da universidade.

Com relação às atividades realizadas pelo PET-EDUCAÇÃO, podemos destacar algumas que envolvem os cursos de graduação do campus Florestal/UFV, como o Ciclo de Seminários PET, as Jornadas PET, Minicursos, Visitas Técnico-científicas, o Cine PET, o PET Feira-Livre e a Tertúlia Dialógica Literária.

O Ciclo de Seminários PET consiste na apresentação de palestras relacionadas a um tema norteador do evento. Cada petiano é responsável por uma palestra, podendo haver professores ou especialistas no assunto, os convidados externos. O ciclo geralmente dura todo o semestre com uma palestra por semana, nos horários de almoço, para maximizar a participação dos estudantes. As Jornadas PET, por sua vez, são eventos que oferecem palestras, oficinas e minicursos ligados a um tema unificador. Alguns Minicursos isolados também são oferecidos de acordo com a demanda dos cursos de graduação do campus Florestal/UFV. As Visitas técnico-científicas são realizadas todo semestre para locais de interesse dos petianos e abertas aos demais alunos do campus. O Cine PET consiste na exibição de um filme indicado por um professor com posterior discussão sobre a temática da obra. Essas atividades são fixas, isto é, ocorrem anualmente, porém, não excluem a realização de outras que possam ser, eventualmente, criadas e desenvolvidas. Por fim, a Tertúlia Dialógica Literária é uma atividade em que há a leitura e discussão de uma obra literária escolhida pelos integrantes do grupo.

Focando nas atividades trabalhadas em escolas e na comunidade, destaca-se o PET Feira-livre e o PET Escola. O primeiro consiste na abordagem de temas gerais que interessem a população. Uma tenda é montada na Feira-livre da cidade de Florestal-MG, onde são realizadas oficinas, discussões e exposições relacionadas ao tema proposto (DA SILVA et al, 2015). No PET Escola, o grupo trabalha dentro de uma escola de ensino básico, abordando temas transversais de forma lúdica. Essas atividades são realizadas anualmente. 
Algumas atividades não são abertas ao público externo, como a reunião para decisões de cunho administrativo e as reuniões temáticas. Esta última tem por finalidade a discussão entre os petianos de temas atuais gerais ou técnicos.

As atividades do PET-EDUCAÇÃO são sempre divulgadas por meio de cartazes impressos e em meio virtual através das mídias sociais, com o intuito de se estender ao maior número de estudantes possível para os eventos e atividades.

\section{A pesquisa realizada}

A coleta de informações foi feita por meio da aplicação de questionários semiestruturados a estudantes de todos os cursos de graduação do campus Florestal da Universidade Federal de Viçosa. Os questionários foram constituídos de seis perguntas, fechadas e abertas, que versavam sobre os objetivos da investigação. As primeiras três perguntas se relacionavam a questionamentos sobre se o entrevistado conhecia o PETEDUCAÇÃO, quais atividades ele conhecia e de quais havia participado. As últimas questões abordavam a percepção do estudante sobre a contribuição das atividades do PET para a sua formação acadêmica, sobre o motivo do mesmo na ausência de atividades e também se ele teria interesse em participar das atividades do programa, listando quais.

Para tratamentos dos dados obtidos por meio de questões abertas, utilizou-se como base o método de análise de conteúdo de Bardin (2016), onde foram criadas categorias temáticas que facilitassem a compreensão do eixo dos discursos dos estudantes. Este método é um instrumento de exploração interpretativa de documentos que permite ao pesquisador obter núcleos de informações e conceitos que revelem os principais temas levantados e que permite selecionar significados relacionados à temática e ao contexto (BARDIN, 2016). As questões fechadas tiveram sua análise baseada em dados quantitativos transformados em porcentagem (\%), organizados em forma de gráficos e tabelas utilizando o programa Microsoft Office Excel 2007.

O objetivo principal dessa pesquisa foi entender qual a percepção que os graduandos do campus Florestal/UFV têm sobre o PET-EDUCAÇÃO, se o conhecem, se participam das atividades e ainda sobre como este contribui para sua formação enquanto cidadão e profissional. Os seguintes questionamentos foram tomados como eixos norteadores dessa investigação: (1) Os graduandos do campus Florestal/UFV conhecem o PET-EDUCAÇÃO? (2) Os graduandos desse mesmo campus participam 
das atividades do PET? (3) Quais atividades são mais frequentadas? (4) Qual a percepção dos estudantes em relação à contribuição do PET-EDUCAÇÃO para a melhoria de sua formação acadêmica?

\section{Resultados e discussões}

\section{Caracterização e perfil dos estudantes investigados}

Foram aplicados 195 questionários distribuídos entres os 10 cursos de graduação do campus Florestal/UFV: os bacharelados (Administração, Agronomia, Ciências da Computação e Engenharia de Alimentos), um tecnólogo (Tecnologia em Gestão Ambiental) e as licenciaturas (Ciências Biológicas, Educação Física, Física, Matemática e Química).

Do total de entrevistados que participaram desta pesquisa, a maior parte cursava Educação Física (21\%), seguida de estudantes de Ciências Biológicas (17\%), Tecnologia em Gestão Ambiental (13\%), Agronomia (13\%), Engenharia de Alimentos (13\%), Química (7\%), Administração (5\%), Matemática (4\%), Física (4\%) e Ciências da Computação (3\%). Com relação ao ano que esses estudantes ingressaram na UFV/Florestal, em sua maioria, foi no período que compreende os anos de 2012 a 2015. A representação de calouros (ingressantes em 2016) chegou a $18 \%$ do total de entrevistados. Ainda caracterizando o público de entrevistados deste trabalho, a maioria (55\%) deles frequenta o campus no período noturno, seguidos de uma grande parcela (39\%) que estão na UFV em período integral e a minoria (6\%) que estão somente no período diurno na universidade (Gráfico 1). Esses dados revelam que ao menos a metade dos entrevistados deste estudo pertence aos cursos noturnos (Administração, Ciências Biológicas, Educação Física e Química).

Gráfico 1: Período em que o estudante de graduação do campus UFV Florestal frequenta a universidade. 


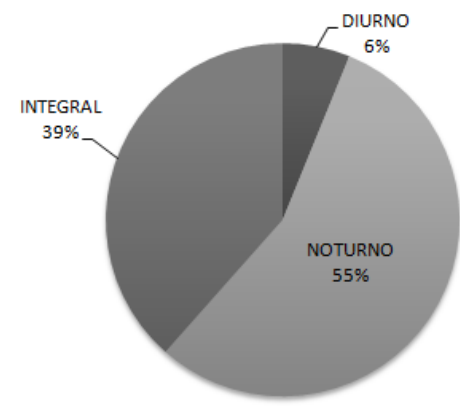

Fonte: Arquivo PET/EDUCAÇÃO (2016).

A maioria desses alunos (57\%) realiza atividade extraclasse e outros (43\%) afirmaram não realizar nenhum tipo de atividade que seja externa às realizadas em sala de aula.

\section{O conhecimento dos graduandos sobre o PET-EDUCAÇÃO e suas atividades}

Quando questionados se conheciam o PET-EDUCAÇÃO, 63\% dos estudantes responderam positivamente, sendo que a maioria (17\%) é estudante do curso de Educação Física, seguido por alunos de Ciências Biológicas (15\%), Química (6\%), Agronomia (6\%), Tecnologia em Gestão Ambiental (5\%), Física (4\%), Engenharia de Alimentos (4\%), Matemática (3\%), Ciências da Computação (2\%) e Administração (1\%). Dos 37\% que não conhecem o programa, os estudantes do curso de Engenharia de Alimentos, Tecnologia em Gestão Ambiental e Agronomia são os mais representados, seguidos pelos demais cursos com menor porcentagem, como mostra o Gráfico 2. Percebe-se que os estudantes das licenciaturas são os que mais conhecem o programa. Esse fato é evidente uma vez que o PET-EDUCAÇÃO, apesar de trabalhar em outras áreas, tem como foco o campo da educação que permeia os estudos dos cursos de licenciatura.

Gráfico 2: Quantificação por curso de alunos que conhecem e que desconhecem o PETEDUCAÇÃO. ADM (Administração); AGR (Agronomia); BIO (Ciências Biológicas);

CDC (Ciências da Computação); EAL (Engenharia de Alimentos); EFI (Educação Física); FIS (Física); MAT (Matemática); QUI (Química); TGA (Tecnologia em Gestão Ambiental). 


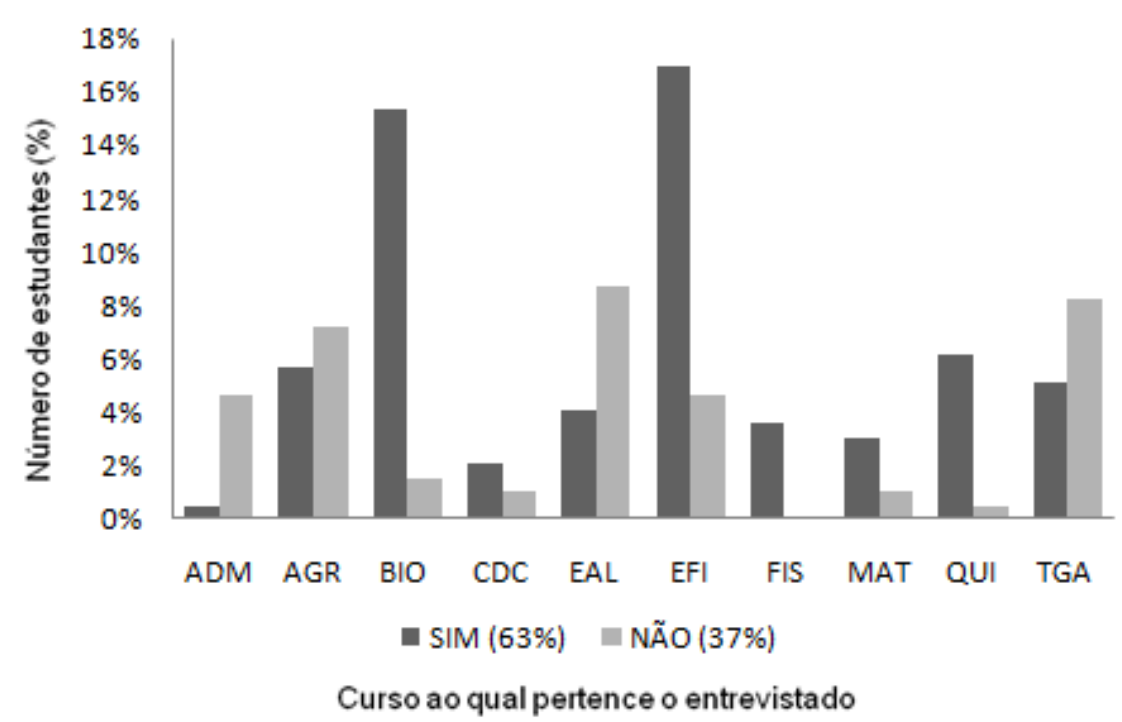

Fonte: Arquivo PET/EDUCAÇÃO (2016)

Os entrevistados que eram cientes da existência do PET-EDUCAÇÃO (63\%) foram questionados sobre quais atividades desenvolvidas pelo programa eles conheciam (Gráfico 3). Das atividades já mencionadas anteriormente, a mais conhecida foi o Ciclo de Seminários PET, citado por $66 \%$ dos alunos. Outras atividades bastante conhecidas são os Minicursos (33\%), seguidos pelas Visitas técnico-científicas (30\%), Jornadas PET (25\%), PET Feira-Livre (17\%), Jornal PET (16\%) e CinePET (10\%). Algumas dessas atividades também aparecem como as mais frequentadas pelos estudantes questionados, sendo que 30\% destes participaram do Ciclo de Seminários, $12 \%$ das Jornadas PET, seguidas pelos Minicursos (11\%), Visitas técnico-científicas (7\%) e CinePET (2\%). Tais atividades são mais voltadas para o público universitário externo ao programa, sendo essa a explicação para o fato de serem as mais conhecidas e frequentadas. Em adição, o Ciclo de Seminários e as Jornadas PET abordam temas relevantes aos cursos de graduação e exploram estes de forma mais profunda do que em sala de aula.

Gráfico 3: Nível de conhecimento demonstrado pelos entrevistados sobre as atividades realizadas pelo PET-EDUCAÇÃO. 


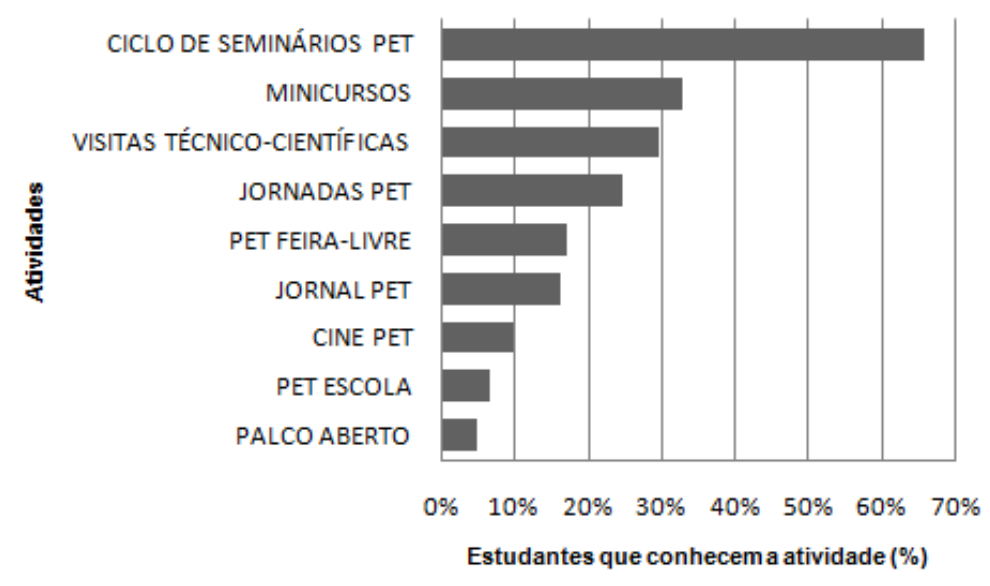

Fonte: Arquivo PET/EDUCAÇÃO (2016)

Das atividades menos conhecidas, pode-se citar o Palco Aberto (5\%), evento que não é realizado mais pelo grupo, e o PET Escola, conhecido por apenas $7 \%$ dos entrevistados, sendo essas também as menos frequentadas (Gráfico 4). O PET Escola é realizado dentro da Escola Municipal Dercy Alves Ribeiro, em Florestal-MG, não tendo como foco o público de graduação, o que explica o baixo conhecimento pelo público universitário.

Dos 122 estudantes que conheciam o PET-EDUCAÇÃO, $51 \%$ não participaram de nenhuma atividade do programa. Quando questionados sobre o motivo da ausência nas atividades, o mais relatado foi a falta de tempo devido ao envolvimento em outras atividades. Esse fato corrobora com os dados levantados a respeito da realização de atividades extraclasse, das quais mais da metade dos alunos (57\%) afirmaram participar. Alguns estudantes também relataram desconhecimento quanto às atividades, podendo ser por falta de divulgação das mesmas ou outros motivos desconhecidos. Uma pequena parcela, em sua maioria dos cursos de bacharelado, também disse não ter frequentado nenhuma atividade por não ter interesse sobre os temas abordados. Isso é compreensível, uma vez que muitos dos temas contemplam o universo educacional, que é o foco do programa e o qual permeia a área de estudo das licenciaturas.

Gráfico 4: Porcentagem de estudantes que frequentaram as atividades do PETEDUCAÇÃO. 


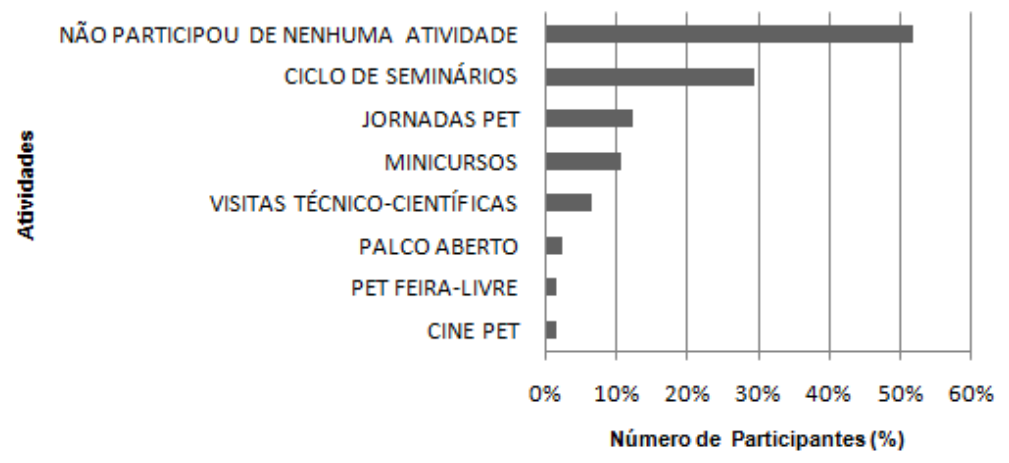

Fonte: Arquivo PET/EDUCAÇÃO (2016)

Os estudantes também foram questionados quanto ao seu interesse em participar das futuras atividades realizadas pelo programa. A maioria (89\%) afirmou ter interesse em participar das próximas atividades, enquanto $11 \%$ responderam de forma negativa. O motivo para uma parcela tão grande querer participar das próximas atividades, ainda que alguns não tenham participado por falta de interesse ou de conhecimento e outros sequer conheciam o PET-EDUCAÇÃO, é pelo fato de que, após a aplicação dos questionários, os petianos falaram sobre o programa e detalharam um pouco mais as atividades como uma forma de divulgação das mesmas. Isso pode ter contribuído para uma expansão do interesse pelos eventos desenvolvidos. Dividindo o interesse por cursos, novamente aparecem na frente os estudantes de Ciências Biológicas e Educação Física como os mais interessados (Gráfico 5).

Entende-se que, realmente, o maior interesse vem dos licenciandos, uma vez que o foco do PET-EDUCAÇÃO é voltado para esse público, mas que os estudantes dos bacharelados também possuem interesse nas atividades, haja vista que, quando tiveram conhecimento do programa por meio das entrevistas, muitos apresentaram desejo de participar dos eventos. Pode-se ter como exemplo os estudantes de Agronomia, Engenharia de Alimentos e Tecnologia em Gestão Ambiental, que conheciam pouco o programa, mas ao tomar ciência do mesmo manifestaram interesse em participar das atividades.

Gráfico 5: Quantificação por curso, de alunos que possuem interesse em participar das atividades futuras do PET-EDUCAÇÃO. ADM (Administração); AGR (Agronomia); BIO (Ciências Biológicas); CDC (Ciências da Computação); EAL (Engenharia de Alimentos); EFI (Educação Física); FIS (Física); MAT (Matemática); QUI (Química); TGA (Tecnologia em Gestão Ambiental). 


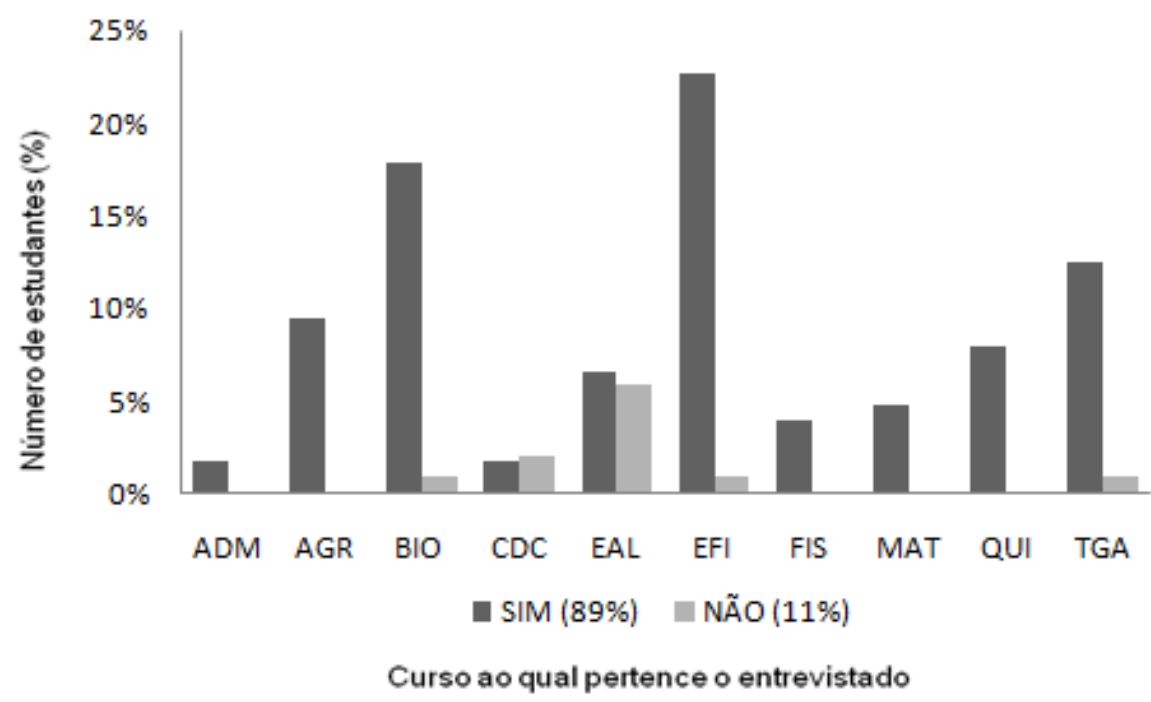

Fonte: Arquivo PET/EDUCAÇÃO (2016)

Aos estudantes que desejavam participar de futuras realizações do PETEDUCAÇÃO, foi perguntado sobre quais atividades especificamente eles se interessavam. As mais citadas foram o Ciclo de Seminários PET (46\%), Minicursos (36\%) e Visitas técnico-científicas, citada por $30 \%$ dos estudantes pesquisados. Também foram citados como interessantes o PET Feira-Livre, Cine PET, Atividades de cunho extensionista e cultural e mesmo o palco aberto, atividade já extinta (Tabela 1). Percebe-se que o Ciclo de Seminários continua liderando entre as atividades mais influentes do programa. Essa atividade é importante, pois, além de preparar os licenciandos para a sua profissão, que exigirá a fala em público e organização de temas a serem discutidos, introduz o público ouvinte a diversos temas que podem ser debatidos. Isso traz uma diversidade de conhecimentos para os sujeitos que estão sendo formados dentro da universidade.

Tabela 1: Reposta dos estudantes de graduação do campus UFV Florestal quanto à quais tipos de atividades realizadas pelo PET-EDUCAÇÃO eles apresentam interesse em participar.

\begin{tabular}{cc}
\hline Opção de atividade & Resposta apontada (\%) \\
\hline Ciclo de Seminários PET & $46 \%$ \\
Minicursos & $36 \%$ \\
Visitas técnico-científicas & $30 \%$ \\
Cine PET & $7 \%$ \\
PET Feira-Livre & $6 \%$ \\
Atividades culturais & $2 \%$ \\
Palco Aberto & $1 \%$ \\
\hline
\end{tabular}

Fonte: Arquivo PET/EDUCAÇÃO (2016) 
Algumas sugestões de atividades também foram dadas pelos estudantes que responderam aos questionários. Das atividades que foram sugeridas e que não são oferecidas pelo PET, vale destacar eventos relacionados à arte e cultura, como dança, teatro etc., e atividades que envolvam a prática de esportes. Atividades culturais já estão sendo propostas em parceria com outros grupos da instituição a fim de sanar a carência nessa área. Um evento, nesse sentido, intitulado "Intervalo Cultural", conta com apresentações quinzenais no campo da música e da dança e oficinas de arte no horário que compreende o almoço dos estudantes, a fim de oferecer um espaço de lazer e exposição de talentos artísticos para os alunos do campus.

\section{A percepção da contribuição do PET-EDUCAÇÃO para a formação do graduando do campus UFV Florestal}

Um dos objetivos desse estudo, como já mencionado, é saber qual a percepção dos estudantes de graduação sobre a contribuição do PET-EDUCAÇÃO do campus UFV Florestal, por meio de suas atividades, para a sua formação acadêmica.

A maioria dos estudantes disseram que o PET EDUCAÇÃO contribuiu/contribui positivamente para sua formação acadêmica, ainda que destacando diferentes vertentes dessa contribuição. As categorias abaixo relatadas foram criadas com base no método de análise de conteúdo de Bardin (2016).

Muitos estudantes afirmaram que o PET contribuiu para a sua formação, pois permitiu a aquisição de conhecimentos sobre diversas temáticas que não eram exploradas em outros contextos, como pode ser evidenciado nas falar a seguir.

(4) O PET me ajudou a adquirir conhecimento sobre temas abordados que eu não conhecia ou que ainda não tinha uma opinião formada sobre.

(8) O programa ampliou meus conhecimentos para determinados assuntos.

Outra contribuição levantada pelos estudantes foi o conhecimento complementar na área de educação que o PET aborda. Uma vez que o PET do campus UFV Florestal tem como foco a grande área da Educação, espera-se que o mesmo contribua em maior parte nesse sentido. Assim, há uma grande contribuição para os alunos da licenciatura, futuros professores, no âmbito da formação para o exercício da docência. Essa categoria 
é muito importante quando se leva em conta a problemática da formação de professores, em que existe uma carência e, por vezes, ineficiência da formação pedagógica oferecida pelos cursos de licenciatura (MALUCELLI, 2001; CHAVES, TERREZAN, 2015). O PET-EDUCAÇÃO, contribui nesse sentido.

(24) [...] Me acrescentou conhecimentos na área de educação/licenciatura.

(49) [...] Me apresentou metodologias de ensino que podem me auxiliar em minhas atividades, em projetos e como futura docente.

Outra contribuição muito relatada pelos estudantes foi o fato do programa, pela realização de diversas atividades e eventos, trazer oportunidades de aquisição de certificados que, na visão dos alunos, enriquecem o currículo. Uma das funções do PET é ampliar a formação não somente dos petianos, mas também dos graduandos de uma forma geral. Uma vez que os certificados fazem parte da comprovação dessa trajetória de formação, o programa também contribui nesse sentido.

As categorias já citadas foram as mais notadas nos discursos dos estudantes. No entanto, outras contribuições também foram levantadas, como o fato de que o programa trouxe conhecimento sobre a vivência universitária através de palestras, conhecimento sobre publicação científica e momentos de lazer. Outra contribuição do PETEDUCAÇÃO relatada foi no âmbito da ampliação do pensamento crítico sobre a sociedade permitido pelas discussões em atividades e eventos que, segundo os estudantes, são muito produtivas. Como exemplificam as falas abaixo:

(28) [...] Contribuiu de forma positiva acrescentando vivência acadêmica e conhecimento de vida.

(19) [...] Me deu uma visão critica das coisas.

(61) De forma positiva, alguns temas como currículo lattes e artigos científicos, me auxiliou na construção do meu currículo, e na formação do meu senso critico.

(54) O PET é o único programa que oferece discussão de temas tanto na área cultural quanto técnica.

Poucos estudantes afirmaram não saber ao certo qual contribuição o PET tem para sua formação ou não viram contribuição. De uma forma geral, os discursos 
evidenciaram a participação positiva que as atividades do PET-EDUCAÇÃO representam na formação acadêmica e social dos estudantes que as frequentaram. $\mathrm{O}$ grupo PET do campus UFV Florestal, assim como diversos outros grupos PET existentes nas universidades brasileiras, tem realizado ações que permitem iniciar não somente os bolsistas, mas os alunos de graduação que tem acesso às atividades do programa, ao pensamento crítico, à responsabilidade social e ao espírito científico. Segundo Martin (2005), essa é uma das características do programa de educação tutorial que o torna mais abrangente que outros programas, como os de iniciação científica, por exemplo.

\section{Considerações finais}

Desta pesquisa, é importante retomar aqui alguns dos resultados mais importantes. Como aspecto positivo, constatou-se que o programa PET-EDUCAÇÃO é bastante conhecido pelos estudantes de graduação do campus Florestal/UFV, principalmente pelos licenciandos. As atividades realizadas também são bastante conhecidas, sendo o Ciclo de Seminários a mais popular dentre todas, seguida das Jornadas PET e Visitas-técnicas. Essas atividades despertam mais a atenção dos graduandos, sendo este um de seus objetivos. A influência das atividades extracurriculares propiciadas pelo PET-EDUCAÇÃO ficou clara nos relatos dos alunos pesquisados. O programa contribui com conhecimentos sobre temas variados, principalmente na área de educação, que é o foco do mesmo. Além disso, traz aos estudantes oportunidades de aquisição de certificados, o que eles consideram importante para a formação acadêmica, conhecimento sobre a vivência universitária, ampliação do pensamento crítico sobre a sociedade e momentos de lazer. Destaca-se a contribuição que as ações do grupo trazem para os licenciandos do campus Florestal/UFV, por meio de atividades que abordem novas metodologias de ensino e discussões acerca das ciências da educação e sobre o ensino de conteúdos específicos.

Um ponto não tão positivo é o fato de que pouco mais da metade dos entrevistados nunca participaram de nenhuma atividade do PET, mesmo conhecendo-as. Isso foi explicado pelo fato de que a maioria desses não dispõe de tempo devido à realização de atividades extraclasse, o que torna o horário que eles têm disponível incompatível com o das atividades e eventos. Alguns estudantes também disseram não participar das atividades por falta de conhecimento das mesmas. No entanto, não se sabe 
se esse desconhecimento se dá por um problema de divulgação do programa, uma vez que alguns estudantes relataram que as atividades são bem divulgadas. É necessário, para isso, um novo estudo nesse sentido, visando melhorar a divulgação das atividades. Ainda assim, a intensificação dessa divulgação pode ser uma estratégia para ampliar o alcance do programa.

Muitos dos estudantes pesquisados, mesmo os que não participaram de nenhuma atividade, manifestaram interesse em fazê-lo futuramente.

Desta forma, fica evidente o quanto o programa é capaz de contribuir no sentido de propiciar atividades extracurriculares que complementem a formação dos graduandos dos cursos de graduação do campus, principalmente no que tange à área pedagógica para os cursos de licenciatura. Considera-se realizar, no futuro, estudos que elucidem o impacto do Programa de Educação Tutorial - PET-EDUCAÇÃO na complementação da formação dos futuros docentes oriundos dos cursos de licenciatura deste campus. Uma vez que é ampla a discussão sobre a formação docente e seus desafios, o PETEDUCAÇÂO pode ser um importante aliado no contexto da formação extracurricular dos futuros professores a serem formados no campus Florestal/UFV.

AGRADECIMENTOS: Fundo Nacional de Desenvolvimento da Educação - FNDE. Agradecemos aos ex-petianos Carla Gabielle Mariana, Haroldo Nazareth Ribeiro e Laís Ferreira Silva pela contribuição com o esforço da coleta de informações, por meio da aplicação dos questionários.

\section{REFERÊNCIAS}

BARDIN, L. Análise de conteúdo. São Paulo, Edições, 2016.

BIASUS, G. Formação de professores nas instituições federais de ensino superior do Estado do RS: um estudo multicasos. 2006. 197 f. (Dissertação), Mestrado em Educação, Universidade Federal de Santa Maria, Santa Maria, 2006.

$\mathrm{BROH}, \mathrm{B}$. Linking extracurricular programming to academic achievement: Who benefits and why? Sociology of education, p. 69-95, 2002.

CHAVES, T. V.; TERRAZAN, E. A. Um estudo sobre as formas de organização da formação pedagógica em cursos de licenciatura. Revista Brasileira de Pesquisa sobre Formação Docente, v. 7, n. 13, p. 31-44, 2015.

DA SILVA, M. M. F. et al. Formação pedagógica em cursos de licenciatura: um estudo de caso. Educação (UFSM), Santa Maria, v. 41, n. 3, p. 593-604, 2016. 
DA SILVA, M. M. F. et al. PET FEIRA-LIVRE: epidemiologia e saúde ambiental através das trocas de experiências com a comunidade de Florestal-MG. Revista ELODiálogos em Extensão, Viçosa, v. 4, n. 1, p. 60-77, 2015.

GATTI, B. A. Formação de professores no Brasil: características e problemas. Revista Educação e Sociedade, Campinas, v. 31, n. 113, p.1355-1379, 2010.

GERBER, S. B. Extracurricular activities and academic achievement. Journal of Research \& Development in Education, 1996.

MALUCELLI, V. M. B. Análise crítica da formação dos profissionais da educação: revisando a licenciatura em Biologia. Revista Diálogo Educacional, Curitiba, v. 2, n. 4, p. 139-152, 2001.

MARTIN, M. G. M. B. O Programa de Educação Tutorial: formação ampla na graduação. 2005. 108 f. (Dissertação), Mestrado em Educação, Universidade Federal do Paraná, Curitiba: 2005.

PEREIRA, A. K. et al. A importância das atividades extracurriculares universitárias para o alcance dos objetivos profissionais dos alunos de administração da Universidade Federal de Santa Catarina. Revista Gestão Universitária na América Latina-GUAL, Florianópolis, v. 4, n. 4, p. 163-194, 2011.

PERES, S. M. et al. O Programa de Educação Tutorial no contexto da graduação em Computação: Perfis, percepções e reflexões. In: WEI-XXII WORKSHOP SOBRE EDUCAÇAO EM COMPUTAÇAO. Anais do XXXIV Congresso da Sociedade Brasileira de Computaçao. 2014. p. 1503-1512. Disponível em:

<http://www.lbd.dcc.ufmg.br/bdbcomp/servlet/Trabalho?id=22789>. Acesso em: 28 out. 2017.

PERES, S. M.; BOSCARIOLI, C. Fortalecendo o ambiente acadêmico da graduação com o Programa de Educação Tutorial do Ministério da Educação. In: CADERNO DE RESUMOS - SEMINÁRIO DE INOVAÇÕES CURRICULARES, Unicamp, 2011.

PROGRAMA DE EDUCAÇÃO TUTORIAL - PET. Manual de Orientações Básicas. Departamento de Modernização e Programas da Educação Superior, Coordenação geral de Relações Acadêmicas de Graduação, Secretaria de Educação Superior, Ministério da Educação, 2006.

SIMÃO, R. I. P. A relação entre atividades extracurriculares e o desempenho acadêmico, motivação, autoconceito e autoestima dos alunos. Monografia do Instituto Superior de Psicologia Aplicada, não publicada. Lisboa, 2005.

USP. Programa de Educação Tutorial - PET/USP: Projeto de Políticas e Diretrizes Pedagógicas. Pró-Reitoria de Graduação, Universidade de São Paulo, 2009. 


\section{Como referenciar este artigo}

SILVA, Mardem Michael Ferreira da.; et al. O pet-educação no contexto da formação acadêmica: as licenciaturas em evidência. Revista on line de Política e Gestão Educacional, Araraquara, v.21, n.3, p. 1499-1516, set./dez. 2017. ISSN: 1519-9029.

Submetido em: 28/10/2017

Aprovado em: 20/12/2017 